Journal of Counselor Practice, 11(1):55-84, 2020

DOI: $10.22229 / \mathrm{ntt} 1112020$

Copyright (C) Ohio Counseling Association

\title{
Navigating the Therapeutic Waters: How Counselors Develop and Utilize their Theoretical Orientation
}

\author{
Diandra J. Prescod ${ }^{1}$ \\ Pennsylvania State University \\ Melissa Zeligman \\ University of Central Florida \\ Jennifer H. Greene \\ Texas State University \\ Kristopher G. Hall \\ University of San Diego
}

Historically, African Americans have lower rates of help seeking as negative perceptions of mental illness and treatment have persisted. Previous researchers identified stigma as an important factor in these attitudes and behaviors. In this current study, 210 African American participants responded to open-ended survey questions assessing these topics. We conducted a qualitative content analysis to identify themes. The themes that emerged included: 1) Stigma: Feeling ashamed and being shamed, (2) Violenceldanger, (3) Perceptions of ability, (4) Indicator of weakness, (5) Dismissing mental health issues, and (6) Religion and spirituality.

Keywords: Theoretical development, Counselors, Theoretical orientation

As counselors progress in their development, choosing a theoretical model is expected at some point during the process. Beginning and more experienced

\footnotetext{
1 Correspondence may be sent to: Diandra J. Prescod, Department of Educational Psychology, Counseling, and Special Education, Pennsylvania State University, 301 CEDAR Building, University Park, PA 16802,(814) 863-8115, prescod@psu.edu.
} 
counselors align with certain theoretical models for various reasons. Studying theoretical orientations usually occurs at the graduate level and many students struggle to find a theoretical model in which they align (Freeman, Hayes, Kuch, \& Taub, 2007). Early on in their training, counseling students work intensely on skill development while considering which theory they might align with (Adams, Vasquez, \& Prengler, 2015). Fitch, Canada and Marshall (2001) conducted a survey to examine which theoretical models were used in CACREP-accredited clinical training master's programs. Cognitive-behavioral and behavioral theories (e.g., CBT, REBT) were used most frequently followed by humanistic theories (e.g., person-centered, Gestalt, and existential). Additionally, in many clinical psychology graduate programs, students might align with a certain orientation because they receive a narrow view of approaches at their learning institution (Heatherington et al., 2012). For example, more clinical programs (i.e., clinical psychology) had a tendency to align with CBT (Heatherington et al., 2012; Ogunfowora \& Drapeau, 2008; Poznanski \& McLennan, 2003) while counseling psychology adhered to more feminist and multicultural models (Ogunfowora \& Drapeau, 2008).

\section{Graduate Students' Training and Theoretical Framework Development}

Because participants in the current study discussed their graduate training in their responses during our interviews, we wanted to include a discussion about graduate student training in our literature discussion. Although certain models are emphasized over others, many textbooks used in counseling graduate programs suggest that students align with one theory in the beginning of their training to allow them to properly utilize one theory (Baruth 
\& Huber, 1985; Capuzzi \& Gross, 2010; Corey, 2012; Frank \& Frank, 1993; Halbur \& Halbur, 2014; Sharf, 2011). It is important to note that the way in which students learn about theories differs. Masters level counselors described the difference between conceptual and experiential learning. Studying various theories came much easier than actually practicing the theory (Auxier, Hughes, \& Kline, 2003). Even in studying concepts, students can have varied experiences; textbooks outline and explain theories differently. Some texts may provide a general idea of theories with advantages and disadvantages while others might do the same and talk about ideas of integration and eclecticism (Brabeck \& Welfel, 1985). Although textbooks might explain theories differently, students are likely to choose a theory they feel better and more comfortable practicing which is why activities such as role-playing are important (Dollarhide, Smith, \& Lemberger, 2007). Feedback from supervisors also influenced identity and theory development (Auxier et al., 2015). Halbur and Halbur (2018) are the authors of a textbook that explore theoretical development in counseling and psychotherapy. The authors help guide students in finding an orientation that aligns with their personal values and introduce the Intentional Theory Selection (ITS) model. The model starts with an introspective examination of one's life philosophy. Finding a counseling theory that is similar to or in line with one's value system is also important for graduate level counselors (Petko, Kendrick, \& Young, 2016).

When graduate students were asked to write an essay explaining which theory was best or most useful, the majority expressed the idea that each theory had advantages and spoke about the importance of eclecticism (Brabeck \& Welfel, 1985). Many counselor educators speak about the importance of integration with their students but agree that the conversation about integration should come after students have a better understanding of 
theory (Marquis, Hudson \& Tursi, 2010). If choosing to work from an eclectic approach, it is important to learn similarities and differences between theories in order to use them together most effectively (Cheston, 2000). Counseling graduate programs that try to train eclectic counselors run into challenges; training a beginning counselor in such a way, properly, is rare (Hollander, 1999; Lazarus \& Beutler, 1993). Commitment, time constraints and consistency are all reasons why this can be quite difficult. Training counselors to be eclectic can lead to confusion rather than deeper understanding for counselors in training (Lazarus \& Beutler, 1993). Whether counselors consider themselves eclectic or not, other things influence theoretical development for counselors.

\section{Experienced Counselors and Theoretical Framework}

Bitar, Bean and Bermudez (2007) found that 10 categories influenced theoretical development of licensed marriage and family therapists; (1) personality, (2) personal philosophy, (3) family of origin, (4) their own therapy, (5) marriage, (6) undergraduate courses, (7) graduate training, (8) clients, (9) professional development, and (10) clinical sophistication. In essence, both personal and professional reasons influence theoretical choice (Halbur \& Halbur, 2014; Southern \& Devlin, 2010). Although this study found personality as something that influenced theoretical choice, another study did not find personality as an influence (Freeman et al., 2007). Profession, gender, and years of clinical experience also influence one's theoretical approach (Ogunfowora \& Drapeau, 2008). Research discusses graduate training, experiential learning, and personal beliefs amongst 
others, as influences on one's theoretical orientation (Auxier et al., 2015; Bitar et al., 2007; Dollarhide et al., 2007).

More experienced counselors find continued learning to be important in finding new ways to assist their clients (Moss, Gibson \& Dollarhide, 2014; Vasco \& Dryden, 1994). Conferences, workshops, classes, and various other trainings allow counselors to learn new ways to work with their clients and enhance their knowledge base. Theoretical approach is further impacted by continued learning (Moss et al,, 2014 and is considered a lifelong process (Southern \& Devlin, 2010). We decided to engage in this study to add to the literature base on how counselors develop their theoretical orientation. Studies exist on the connection between theoretical orientation and treatment outcomes (Holm, Bevly, \& Prosek, 2018; Lambert, 2015; Stiles, Barkham, Mellor-Clark, \& Connell, 2008), but few in very recent years have solely examined theoretical development.

\section{Purpose of Study}

For the purposes of this study, the researchers defined theoretical approach as concepts and ideas that provide a framework for the counseling experience (Corey, 2012). This qualitative study examined interviews conducted with practicing counselors and through the use of qualitative methods, the researchers aimed to examine the following research questions:

1. How does counseling theory development occur in practicing counselors?

2. What sources of influence encourage development of theoretical orientation for professional counselors? 
3. How do counselors utilize their theoretical orientation in their current practice?

\section{Method}

\section{Participants}

Participants were selected using a purposive random sampling method within a specific geographical location. The geographical location was chosen due to proximity to the research team and the large number of counselors in the area. This participant selection method resulted in nine counselors being interviewed with all nine interviews included in the analyses. Participants were seven males and two females and all identified as Caucasian/White. The professional experience of participants ranged from 7 to over 30 years as counselors. Six of the participants worked in a private practice and three worked as instructors in graduate counseling programs teaching courses such as practicum, internship and counseling theory. At the undergraduate level, four participants had a background in psychology, two majored in communications, and we did not have that information for three of our counselors. Participants identified a range of current theoretical orientations including humanistic, CBT, and integrative/eclectic. Five of the nine participants identified themselves as either integrative or eclectic, often in addition to another theoretical orientation.

\section{Procedures}


The research team obtained approval from the university's Institutional Review Board (IRB) before conducting this study. The potential participant pool was made up of licensed mental health counselors who were at least 5 years post-masters. We wanted participants who were at least 5 years post-masters to create some distance and professional experience between one's graduate program. This potential participant pool was created by using a random number generator to randomly select from the list of licensed counselors within the research area (i.e. a city in the southeastern United States). Members of the research team contacted potential participants to assess interest in participating in the research. If the potential participant was interested, an interview was scheduled. If the potential participant was not interested or did not respond, the next randomly selected counselor who met the criteria was contacted.

Those who agreed to participate in the study were provided with an informed consent that was explained by a member of the research team. We explained that a certain number of steps would be followed to ensure confidentiality including no names of participants on electronic documents and the master participant list and other documents were password protected. We discuss research biases in our positionality statement below.

\section{Data Collection}

Maypole and Davies (2001) examined perceptions of constructivist learning among students in a community college and found that student experiences were in line with constructivist teaching; students described thinking more critically in independently about the content. Similar to Maypole and Davies (2001), the current study's data were collected 
using phenomenological research methodology (Creswell \& Poth, 2017; Groenewald, 2004; Howard, 1985; Lauer, 1958). To this end, the researchers bracketed the research by meeting prior to data collection to discuss their own beliefs and potential biases concerning counseling theory and theoretical development. The interview questions were developed to be intentionally open-ended and not reflect those biases. The interviews were conducted in participants' offices at times that were convenient to them. The interviews were made up of a variety of open-ended questions including the following: asking participants to speak about when they were introduced to theory, which theory they connected with early on, and how they apply their current theory day to day. Seven questions were asked to facilitate an in-depth discussion surrounding theoretical orientation and each interview lasted approximately 45 minutes. All interviews were recorded and transcribed. The seven questions we asked were as follows:

1. Please describe some early experiences that lead you to choose counseling as your profession.

2. When was the first time you learned about theories?

3. What theories interest you?

4. Please describe your current theoretical orientation.

5. How do you apply your theory day to day with client?

6. Do you think it's important to practice from a particular theoretical orientation?

7. What influenced or facilitated your theoretical development?

\section{Data Analysis}


Phenomenological research seeks to understand how people construct meaning and explain a lived experience (Creswell \& Poth, 2017; Groenewald, 2004; Maypole \& Davies, 2001; Moustakas, 1994). All interviews were audio recorded and transcribed for data analysis purposes. After transcribing verbatim, the researchers individually coded responses from the participant interviews. We then defined all codes and specified the location of each code into one large textual database. The research team then came together after individual coding to agree on group codes and decide which ones should be collapsed or consolidated (Glesne, 2015). We did not agree on codes when we first met because clarification was needed on how and why we each grouped them the way we did. If one person out of the team disagreed with the grouping of codes, we would listen to their rationale and discuss further until we agreed. The codes were then formed into themes, by the entire research team, and examined in depth to answer our research question. Each theme included a number of categories that described the participant's experiences. As a form of triangulation (Groenewald, 2004) in trying to further understand this phenomenon, we conducted a second review of the data and the research team revealed no additional categories or themes. It is important to note that during the research process, we transitioned from doctoral students to assistant professors. We collected and transcribed the data as doctoral students and completed data analysis as assistant professors at universities across the country.

In order to achieve trustworthiness and validity, the research team remained aware of phenomenological methodology. Bracketing, setting aside personal judgment and experiences, is of great importance in phenomenological research. Throughout the process, we tried to approach the data without allowing personal experience to interfere. We 
achieved dependability, ensuring that the whole process was traceable and documented (Lincoln \& Guba, 1985), by engaging in self-reflection using reflexive journaling. This process also contributed to the trustworthiness of the research (Creswell \& Poth, 2017; Glaser \& Strauss, 1967) because it allowed us to document our personal beliefs and attitudes. Ortlipp (2008) describes journaling after each experience in the research (interviews, coding, research write-up) process as a way to stay transparent. We noted our thoughts, opinions, and ideas we had after each part of the process and engaged in dialogue to voice any concerns.

The data were analyzed through content analysis utilizing the entire research team. The initial coding involved half the research team with the other half checking for consistency and missed codes. Using the process described by Hsieh and Shannon (2005), we first read the data as a whole, then read it by paying attention to the words in order to start highlighting common thoughts in the data. After highlighting, we took notes on emerging codes and came together to discuss the codes we took from the data. After agreeing on codes, we discussed themes. Themes emerged through the consensus of the entire team. Due to the length of the interviews and the schedules of the participants, member checking was not utilized. Instead, an outside auditor rechecked all of the codes and themes for validity.

\section{Positionality}

Phenomenological research requires researchers to be aware of their own judgments and ways they can negatively influence how data is analyzed (Creswell \& Poth, 
2017; Maypole \& Davies, 2001; Moustakas, 1994). At the time of data collection, all four researchers were doctoral students in a Counselor Education and Supervision program at a large university in the southeast. Three of the researchers identified as female and one as male; two researchers identified as White and two researchers identified as Black/African American. All had experience in school or mental health counseling prior to conducting the interviews and identified with one particular theoretical orientation. The researchers interviewed participants and engaged in conversations about a topic they are familiar with (i.e. theoretical orientation). They each had to set their personal ideas about theoretical orientation development aside when analyzing the data in order to maintain validity (Creswell \& Poth, 2017; Glesne, 2015). Additionally, two researchers discussed religion and spirituality in their positionality; one being cautious about including religion in work as a counselor and the other having an interest in hearing comments about religion and spirituality.

All of the researchers are currently assistant professors in counseling or counselor education programs where they are teaching courses and conducting research. During their first years in their positions, they taught group, career, theories, internship, human development, and clinical skills courses. Because of teaching these courses, the researchers were engaged in research surrounding counselors and counselor education. In experiencing our first year in assistant professor positions and being relatively new to qualitative research, we were committed to analyzing this data appropriately and completing a sound study.

\section{Results}


The purpose of the research was to identify counselor's perceptions of how counseling theory development occurs. Data analysis produced eight themes (with two having addition sub-themes): (a) career and theory choice personal to therapist, with the sub-theme of spirituality/religion, (b) theory development, (c) process of client change, (d) theoretical approach, (e) exposure to theories, (f) importance of guiding theory, (g) eclectic/integrative, and (h) relationships central to theory, with a sub-theme of clients. Each of these themes is described in detail below.

\section{Research Question 1}

Career and Theory Choice Personal to Counselor. Each of the counselors participating identified ways in which their theory development emerged from personal experiences, or represented personal aspects of themselves. Participants spoke of personal life experiences that initiated career changes and led them into the field of counseling. Multiple participants credited this career change to the recognition that they were already using counseling related tools unofficially in their previous careers, and decided it was time to use these skills more formally through a change in profession. One participant stated, "I found myself doing a lot of brief counseling, so I made a conscious effort to return to school to obtain the credentials to essentially do that..." Another participant had a similar experience which led him into counseling, sharing "I would listen to people's problems all the time and people felt comfortable...so I um found out that I enjoyed listening to people and helping to facilitate their story." 
In addition to one's counseling career path feeling personal, participants admitted that theory selection was also a personal decision. One participant shared their theory selection came about because "I think I understand it and it relates to my personality and to what I think is going to help people." Furthermore, as much as counselors' personal lives seemed to influence theory selection, one's theory also had an impact on their personal lives. While attending a training on a particular theory, one participant found that learning about the theory "literally shifted and transformed my own marriage." Having a personal attachment to a theory brought confidence in working with others in a similar way; with a participant sharing, "it is nice to be able to work with people in a way that I live."

Spirituality. Within this theme, a sub-theme of spirituality and religion emerged from the transcripts. Although the terms spirituality and religion are often used interchangeably, spirituality refers to an individualistic and personal phenomenon (Hall, Dixon, \& Mauzey, 2004), making this sub-theme a natural fit for this theme. Participants spoke on their own sense of spirituality, and how they were particularly drawn to theories that infused similar teachings. "I do study Buddhism, so I know about mindfulness... and I'm a meditator and I would like to recommend to everybody that they meditate." Similarly, another participant said, "I do Christian counseling...so I'm more drawn to theoretical approaches that integrate and support that as opposed to some of the more secular approaches that do not." Lastly, one participant saw a link between spirituality and client wellness, "I see a lack of faith, a lack of belief in something whether it be God or whatever, is really counterproductive in wellness." 
Theory Development. In line with the aims of this research project, a theme emerged describing ways in which clinicians' theoretical orientations developed. Participants described their theoretical orientations as having evolved and as something that grew as they accrued more experience in the field. In addition, participants credited their clients for assisting in theory selection, as they cited lessons learned from clients as influencing their theory development. "I learn a lot from clients. They teach me a lot, so I'm always growing." The process of theory development was reported as gaining stability while gaining experience and beginning to recognize what worked for them and their clients. One participant stated that they became so dedicated to their theory, which worked best with couples and families, that after decades of being in practice they made the decision to discontinue seeing individual clients. Furthermore, participants described their theory as becoming part of their language because they came to know it so well. "I think in order to be fluid you have to know it well enough." Lastly, participants shared that they preferred theories that were concise and logical as they began to develop their theoretical orientations, with one participant stating "it explained what I already thought in a way that made sense."

\section{Research Question 2}

Process of Client Change. Participants partnered their discussions of theory development with personal narratives of how they witnessed change in their own clients, elements they found central to the process of client change (i.e., challenging or confronting 
clients), and their belief that client change was essential in the process of healing. Participants spoke of changes they had seen in their clients, because of their work in therapy, such as a participant who stated they knew change had occurred when their client had obtained a job and successfully navigated their divorce. Further, a participant spoke of how happy she was for her client when the client called years later to share of successes she had in her life since the end of their therapeutic relationship. Participating counselors were able to use these moments of recognized client change as personal feedback that their approach with the client had been appropriate and successful. Those moments lessened the chance that the counselor would consider changing their approach. In addition to speaking of client change they had witnessed firsthand, participants shared that they viewed client change as necessary in moving towards client healing, and that challenging their clients was integral in promoting such change.

Theoretical Approach. The process of theory development was not always linear for the counselors interviewed. Each of the counselors spoke of their initial theoretical approaches, oftentimes pointing out that these were not consistent with the current theories they used in practice. Changes in theoretical approaches were sometimes influenced by the type of work participants found themselves in, such as a participant who felt she "had to get up to speed fast" on EMDR, although a technique, after witnessing a significant amount of trauma in her client load. Participants appeared excited to share of the theoretical orientations they have found meaningful in their practice, as evidenced in their willingness to educate the researchers about various theories throughout the interview process. Participants represented a diverse array of initial and current theoretical orientations, but 
seemed to align with a greater number of theories currently, as opposed to when first starting their careers. Initial and current theoretical orientations of participating counselors can be seen in Table 1.

\section{Table 1}

Participant Theoretical Approaches Initial Theoretical Orientation

Person Centered

Psychoanalytic

Reality Therapy

\section{Current Theoretical Orientation}

Person Centered

Systems Approach

Cognitive Behavioral

Intra-Family Systems

Humanistic

Attachment Theory

Reality Therapy

Acceptance Commitment Therapy (ACT)

Gestalt

Psychodrama

Exposure to Theories. Participating counselors spoke at length about when and how they were initially exposed to various counseling theories. For many of the participants, this exposure took place in a formal educational setting, either at the 
undergraduate or graduate levels and sometimes both. One participant shared that colleagues helped to further broaden their exposure to theories once they were in the field, saying "one of my colleagues was a radical behaviorist, and taught me all about radical behaviorism... and I fell in love with that." Aside from colleagues, mentors were mentioned repeatedly in the transcripts as the way in which participants were exposed to counseling, counseling theories, and treatment approaches.

Additional ways in which participants were exposed to counseling theories included groups, pioneers in the field, and on the job learning. Participants' citing theories exposure through so many outlets outside of educational settings is perhaps due in part to their acknowledgment that they were provided with a limited view of theories within school. "I was first introduced to theories that did not interest me...I was dissatisfied with the promotion of very limited theoretical points of view."

\section{Research Question 3}

Importance of Guiding Theory. An apparent divide existed between participants who felt aligning with a singular guiding theory was important for clinicians, and those who felt eclectic or integrative approaches were more effective (this camp of participants will be described in the next theme). Those who shared of a need for a guiding theory reported that "as I've dabbled in other theories and techniques...this is still my home base." Amongst this camp also existed the fear that "too many theories leads to a lack of intentionality", and further, clinicians who are caught in this cycle "can't articulate what it is they're doing or why they're doing it..." 
Regardless of whether participants supported eclecticism or strong identification with a singular theory, participants seemed to agree unanimously that eclecticism was not developmentally appropriate for new counselors, and that proficiency was needed before one could take a more eclectic theoretical approach. When referring to counselors in training, one participant noted, "I think it's unreasonable to ask them to be eclectic because what I found that to equate to over the years is this like hodgepodge and lack of intention..." Participants agreed that a more appropriate approach for new counselors would be "starting with one [theory] and honing that and then adding as you develop." Adding to this view, another participant stated "...someone who is studying counseling, give them that manualized therapy, an empirically validated therapy. They need to know that, it is valuable for them."

In contrast to those counselors who felt a singular guiding approach was essential to their work with clients, other participants felt a more flexible style allowed them the freedom to follow clients wherever they may lead them. Similarly, another participant noted that following one theory felt limiting to their practice, and that they felt more comfortable knowing about a multitude of theoretical approaches. Participants then went on to share ways in which they had utilized various theoretical approaches with clients with differing and unique needs. Further, participants described having "different theories for different modalities" (e.g., groups, individuals, couples). In sum, clinicians who identified with a more eclectic or integrative approach seemed to favor such an approach due to its ability for client type to influence the theory they used. In agreement with the last theme, and the idea that an eclectic approach may not be most appropriate for new counselors, 
clients who preferred eclecticism admitted that such an approach came as they became more comfortable in their role as counselor.

Relationships Central to Theory. Despite the way in which participants described their theory development, or whether they aligned with a singular or more eclectic approach, an overwhelming message that emerged from the data was the idea that relationships with clients are central to one's clinical work. Further, many participants stated that relationships were central to their theoretical orientation, and influenced the way in which they chose and utilized a theory in practice. One participant even warned that in the process of theory selection clinicians must be careful not to sacrifice the therapeutic relationship. Clinicians reported that relationships were so integral to their work, that the goal of nurturing the therapeutic relationship, and catering to the needs of specific clients, often eclipsed and informed the use of theories. These notions are summarized in the subtheme, "clients", below.

Clients. Central to this subtheme, which emphasizes the importance of focusing on clients, and putting the client/counselor relationship first, is the idea that counselors being present with their clients is as essential as the theoretical approach they use. When referring to the power of being with a client, one participant stated, "I don't have to learn any special code, or key, or secret things, or anything, all I have to do is listen." One participant summed this notion of being present and available for a client before all else, by saying:

Sometimes I think that the best thing you can do for your client is to show up, sit here, ask the client if they can make themselves comfortable, and stay here. Stay. If they are going to be screaming, and ranting, crying, and telling you about the 
awful things that happened to them, and you can stay with it when they are in that place, and be steady, be like a rock, I am here.

Participants further stated that focusing on the client first allowed them to choose a theoretical approach that proved effective with clients, or even to use a client as a guide for choosing a theoretical approach. "Each person is different. Each situation is different. You can't give the same format to every person." Another participant echoed this sentiment by acknowledging that he sometimes finds himself making changes to his theory in order to better serve a client. This idea of clients guiding theory selection seemed all the more important when considering one participants sentiment that clients are the most important thing in one's practice.

\section{Discussion}

Our study examined the theoretical development of nine practicing counselors and we structured our study around three research questions. The first question asked how counseling theory development occurs in practicing counselors and two themes emerged that helped us answer that question; career and theory choice and theory development. Similarly to other studies participants discussed personal experiences that initiated career change, and choosing a theory that was in line with their own personality (Bitar et alk., 2007; Petko et al., 2016) as being part of their orientation choice. The second research question asked what sources of influence encourage development of theoretical orientation for professional counselors and the following themes connected to that question; process 
of client change, theoretical approach, and exposure to theories. Seeing change in clients, the type of work one is engaged in (Southern \& Delvin, 2010), and exposure to theory in formal education settings or through mentors (Auxier et al., 2015) were factors that influence orientation development. Lastly, we wanted to examine how counselors utilize their theoretical orientation in their current practice and importance of a guiding theory and relationships central to theory are the two theories that connected to that question. Similarly to what Halbur \& Halbur (2014) discuss, many participants believe in aligning with one theory to make to aid in the development of one's orientation. Some participants discussed the importance of integrated approach which Lazarus (1981) also states.

\section{Implications}

Understanding the theory development of practicing counselors has implications for counselors themselves and for those who train them. Many counselors are first exposed to counseling theories in formal educational settings (Bitar, 2007), which speaks to the important role of counselor educators in providing training in theories with both breadth and depth. Though several participants spoke positively of their early training in theories, several found that early training to be lacking. Through a survey of counselor educators, Marquis and colleagues (2010) found that the discussion of an integrated approach might be premature with novice counselors and should wait until students have a more mature understanding of theory. This finding has implications for how standards outline the discussion of theory with students. The quality of training that counseling students receive should constantly be evaluated and improved in counseling training programs (Council for 
the Accreditation of Counseling and Related Education Programs [CACREP], 2016). This would include training in theoretical orientation.

Furthermore, a thread that ran through many of the interviews was the importance of personal views and personal experiences on theory selection. Counselor educators can incorporate this personal knowledge and preference into theories classes through reflection exercises and activities. Activities like this can help make the process more personal from the beginning of training. Drawing on personal experiences helps many counselors identify their theoretical orientation (Bitar et al., 2007; Halbur \& Halbur, 2014; Southern \& Devlin, 2010). These type of reflective assignments can be and often are incorporated throughout counselor training programs. It is important to note, however, that if left unchecked, personal views and experiences can bias one's development. Part of the reflection process should include a discussion of these biases.

In addition to personal views affecting theory selection and changes, participants cited their clients as another reason that they changed their theoretical orientation or incorporated other theories. One suggested formula depicting client change says that adding cognition and feeling yields meaning which leads to awareness. Awareness leads to insight, which in turn facilitates change. This type of equation could aid beginning counselors learn which theory they align with (Adams et al., 2015).

Almost all participants agreed that choosing an initial guiding theory or manualized treatment and learning it well is important for beginning counselors. Gerhardt (2016) and Halbur and Halbur (2014) believe that a grounded theory helps beginning counselors guild confidence in themselves. Building on that, many participating counselors discussed the importance of eclecticism or integrative theories in their own work. Lazarus (1981) and 
Lazarus \& Beutler (1993) state that learning a single orientation can be limiting and suggest that beginning counselors also be exposed to a more integrative approach. This is important for counselor educators to know so that students can be taught individual theories and encouraged to choose one to operate from initially. Yet, counselor education programs should also include a component of what eclecticism and integration are and how to apply them properly. This can and should include information about technical eclecticism, theoretical eclecticism, and integrative theories.

Counselor education graduate programs should inquire about information of former students including; the setting in which counselors practice after they graduate, job satisfaction, and continued education to have a better understanding of what happens with counselors after they leave their training programs and begin practicing. This information helps to inform what training is effective and what needs to be done differently which is why CACREP wants to know similar information (CACREP, 2016). For example, if a high percentage of students do not continue in the counseling field, or believe their training was not useful, a program would have reason to revisit their guidelines and explores areas of improvement. Operating from a theoretical orientation affects every aspect of how counselors practice from initial questions to client conceptualization and goal setting. Understanding how and why counselors choose or change their theoretical orientation is therefore critical to successfully training future counselors.

\section{Limitations and Future Directions}


Despite robust implications, there are limitations to the study that must be considered. Limitations inherent to qualitative methodology include limited generalization due to the small pool of participants (Creswell \& Poth, 2017). Additionally, the use of purposive sampling from a very specific set of possible participants may have limited the variety of possible responses. The authors also did not use other methods for triangulation such as outside auditors, field notes, or participant review, methods which would have improved trustworthiness and rigor (Carlson, 2010; Creswell \& Poth, 2017).

The authors of this research believe that more qualitative inquiry is still necessary for this subject. Future studies may include a grounded theory investigation to develop a more concrete understanding of how theory is developed. This may include more questions regarding how personal reflection and client issues influence theory choice. Other possibilities include an Adelphi study that could include a panel of master counselors and counselor educators. The panel may give insight into how an initial, guiding theory choice evolves into the eclectic integration of theory described by many of the participants. Replications of this study should employ a more varied pool of participants for richer data. Finally, future researchers should include additional measures for trustworthiness and rigor to strengthen the results of the work.

\section{Conclusion}

The purpose of this study was to investigate how counselors in the field develop their personal theories used during therapy. The authors used phenomenological qualitative inquiry in the form of interviews to collect data on the phenomena. After transcription, data 
was analyzed using line-by-line coding to ascertain five primary themes that included exposure to theories, importance of guiding theory, eclectic/integrative, theory development, and the importance of relationships being central to theory, all emerged. Despite limitations, the authors believe there are several implications for this work, including new knowledge regarding how counselors use personal reflection and client analysis to choose theory. Future work in this area should include a more robust sample size and increased measures for triangulation. 


\section{References}

Adams, S. A., Vasquez, A., \& Prengler, M. (2015). A counseling formula: Introducing beginning counseling students to basic skills. The Professional Counselor, 5(1), 114-123.

Auxier, C.R., Hughes, F.R., \& Kline, W.B. (2003). Identity development in counselorsin-training. Counselor Education \& Supervision, 43(1), 25-38.

Baruth, L. G. \& Huber, C. H. (1985). Counseling and psychotherapy: Theoretical analysis and skills applications. Columbus, $\mathrm{OH}$ : Merrill.

Bitar, G. W., Bean, R. A., \& Bermudez, M. (2007). Influences and processes in theoretical orientation development: A grounded theory pilot study. The American Journal of Family Therapy, 35(2), 109-121.

Brabeck, M. M. \& Welfel, E. R. (1985). Counseling theory: Understanding the trend toward eclecticism from a developmental perspective. Journal of Counseling and Development, 63(6), 343-348. Add issue \# only if no doi available for publication, which does happen at times for some publications.

Capuzzi, D. \& Gross, D. R. (2010). Counseling and psychotherapy: Theories and interventions. Columbus, $\mathrm{OH}$ : Merrill.

Carlson, J. A. (2010). Avoiding traps in member checking. The Qualitative Report, 15(5), 1102- 1113.

Cheston, S. E. (2000). A new paradigm for teaching counseling theory and practice. Counselor Education \& Supervision, 39(4), 254-270. 
Corey, G. (2012). Theory and practice of counseling and psychotherapy. Pacific Grove, CA: Brooks/Cole.

Council for Accreditation of Counseling and Related Educational Programs. (2016). The 2016 Standards. Alexandria, VA: Author.

Creswell, J. W., \& Poth, C.N. (2017). Qualitative inquiry \& research design; Choosing among give approaches (4th ed.). Thousand Oaks, California: SAGE publications.

Dollarhide, C. T., Smith, A. T., \& Lemberger, M.E. (2007). Counseling made transparent: Pedagogy for a counseling theories course. Counselor Education \& Supervision, 46, 242-253.

Fitch, T. J., Canada, R., \& Marshall, J. L. (2001). The exposure of counseling practicum students to humanistic counseling theories: A survey of CACREP programs. Journal of Humanistic Counseling, Education and Development, 40 (issue \#), 232242.

Frank, J. D., \& Frank, J. B. (1993). Persuasion and healing. Baltimore: Johns Hopkins University Press.

Freeman, M. S., Hayes, B. G., Kuch, T. H., \& Taub, G. (2007). Personality: A predictor of theoretical orientation of students enrolled in a counseling theories course. Counselor Education \& Supervision, 46(4), 254-265.

Gerhardt, D.R. (2016). Theory and treatment planning in counseling and psychotherapy. Boston, MA: Cengage Learning.

Glaser, B.G., \& Strauss, A.L. (1967). The discovery of grounded theory. Chicago: Aldine. 
Glesne, C. (2015). Becoming qualitative researchers: An introduction (5th ed.). New York, NY: Pearson.

Groenewald, T. (2004). A phenomenological research design illustrated. International Journal of Qualitative Methods, 3, 2-26.

Halbur, D. A. \& Halbur, K. V. (2014). Developing your theoretical orientation in counseling and psychotherapy ( $3^{\text {rd }}$ ed.). Pearson publications.

Hall, C. R., Dixon, W. A., Mauzey, E. D (2004). Spirituality and religion: Implications for counselors. Journal of Counseling and Development, 82, 504-507.

Heatherington, L., Messer, S. B., Angus, L., Strauman, T. J., Friedlander, M. L., \& Kolden, G. G. (2012). Clinical Psychology Science and Practice, 19(4), 364-374.

Holm, J., Bevly, C., \& Prosek, E. (2018). The Relationship Between Counseling Students' Theoretical Orientation and Treatment Outcomes. The Journal of Counselor Preparation and Supervision, 11(2). Retrieved from https://repository.wcsu.edu/jcps/vol11/iss2/4

Howard, G. (1985). Basic research methods in the social sciences. London: Foreman. Hsieh, H.F. \& Shannon, S.E. (2005). Three approaches to qualitative content analysis. Qualitative Health Research, 15(9), 1277-1288.

Lambert, M. J. (2015). Effectiveness of psychotherapeutic treatment. E-Journal for Biopsychosiziale Dialoge in Psychotherapie, Supervision und Beratung, 87-100.

Lauer, Q. (1958). Phenomenology: Its genesis and prospects. New York: Harper. Lazarus, A.A. (1981). The practice of multimodal therapy. New York, NY: McGrawHill . 
Lazarus, A. A. \& Beutler, L. E. (1993). On technical eclecticism. Journal of Counseling and Development, 71(4), 381-385.

Marquis, A., Hudson, D., \& Tursi, M. (2010). Perceptions of counseling integration: A survey of counselor educators. Journal of Counselor Preparation and Supervision, 2(1), 61-73.

Maypole, J., \& Davies, T.G. (2001). Students' perceptions of constructivist learning in a community college American history II. Community College Review, 29(2), 5480.

Moss, J. M., Gibson, D. M., \& Dollarhide, C. T. (2014). Professional identity development: A grounded theory of transformational tasks of counselors. Journal of Counseling \& Development, 92(1), 3-12.

Moustakas, C. (1994). Phenomenological research methods. Thousand Oaks, CA: Sage.

Ogunfowora, B. \& Drapeau, M. (2008). Comparing counseling and clinical psychology practitioners: Similarities and differences on theoretical orientations revisited. International Journal of Advanced Counselling, 30(2), 93-103.

Ortlipp, M. (2008). Keeping and using reflective journals in the qualitative research process. The Qualitative Report, 13(4), 695-705.

Petko, J.T., Kendrick, E., \& Young, M.E. (2016). Selecting a theory of counseling: What influences a counseling student to choose?. Universal Journal of Psychology, 4(6), 285-291.

Poznanski, J. J. \& McLennan, J. (2003). Becoming a psychologist with a particular theoretical orientation to counselling practice. Australian Psychologist, 38(3), 223-226. 
Sharf, R. S. (2011). The theories of psychotherapy and counseling (2nd ed.). Belmont, CA: Brooks/Cole.

Southern, S. \& Devlin, J. (2010). Theory development: A bridge between practice and research. The Family Journal: Counseling and Therapy for Couples and Families, 18(1), 84-87.

Stiles, W. B., Barkham, M., Mellor-Clark, J., \& Connell, J. (2008). Effectiveness of cognitive- behavioural, person-centered, and psychodynamic therapies in UK primary-care routine practice: Replication in a larger sample. Psychological Medicine, 38, 677-688. doi:10.1017/S0033291707001511

Vasco, A. B. \& Dryden, W. (1994). The development of psychotherapists' theoretical orientation and clinical practice. British Journal of Guidance and Counselling, 22(3), 327-341. 